\title{
IMMUNSTÄRKUNG MIT WESTLICHEN KRÄUTERN
}

\section{Sehr geehrte Frau Kollegin, sehr geehrter Herr Kollege!}

Der Herbst kommt auf uns zu und damit die Zeit der Immunschwächen des Atemtrakts. Es ist geradezu eine Freude, diese Problematik mit Akupunktur und Laserung zu behandeln - so gut sind die Erfolge, unkompliziert die Vorgangsweise, ohne Nebenwirkungen und meist hocheffektiv. Doch immer wieder stößt man auf Patienten, die nicht so einfach therapierbar sind. Entsprechend meiner Erfahrung schlage ich Ihnen vor, in diesen Fällen die Akupunktur mit Phytotherapie zu ergänzen. Ich möchte Ihnen sehr gerne eine Teemischung präsentieren, die sich für diese Indikation seit Jahren bewährt:

$\begin{array}{lr}\text { Rp. } & \\ \text { Rx. Astragali } & 10 \mathrm{~g} \\ \text { Pfefferminze } & 5 \mathrm{~g} \\ \text { Schafgarbe } & 10 \mathrm{~g} \\ \text { Echinacea } & 10 \mathrm{~g} \\ \text { Thymian } & 10 \mathrm{~g} \\ \text { Berberitze } & 5 \mathrm{~g} \\ \text { Salbei } & 5 \mathrm{~g} \\ \text { Eibischwurzel } & 5 \mathrm{~g} \\ \text { Oregano } & 5 \mathrm{~g} \\ \text { Ingwer } & 10 \mathrm{~g} \\ \text { Süßholz } & 5 \mathrm{~g} \\ \text { Eukalyptus } & 5 \mathrm{~g} \\ \text { Katzenkralle/Krallendorn } & 10 \mathrm{~g} \\ \text { Teufelskralle } & 10 \mathrm{~g}\end{array}$

$\begin{array}{lr}\text { Bibernelle } & 5 \mathrm{~g} \\ \text { Thuja/Lebensbaum } & 5 \mathrm{~g} \\ \text { Enzianwurzel } & 5 \mathrm{~g} \\ \text { Myrrhe } & 5 \mathrm{~g} \\ \text { Angelikawurzel } & 5 \mathrm{~g} \\ \text { Brunnenkresse } & 10 \mathrm{~g} \\ \text { Hollunderblüten } & 10 \mathrm{~g} \\ \text { Lindenblüten } & 10 \mathrm{~g} \\ \text { Wacholderbeeren } & 10 \mathrm{~g}\end{array}$

Diese Mischung enthält alle europäischen Kräuter, die auf das Immunsystem anregend und modulierend wirken, zudem die chinesische Astragalus-Wurzel. Man nehme von dieser Kräutermischung 4 Teelöffel, überbrüht sie mit 1 Liter kochendem Wasser, lässt 10 Minuten ziehen, seiht ab und trinkt den warmen Tee über den Tag verteilt.

Ich wünsche Ihnen einen gesunden, erfolgreichen Herbst 2018 !

Ihr

Prof. Dr. med. Leopold Dorfer

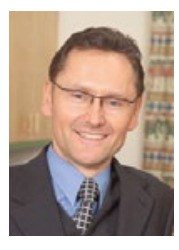

Prof. Dr. med. Leopold Dorfer

Präsident der Österreichischen Gesellschaft für Kontrollierte Akupunktur und TCM (OGKA)

Glacisstraße 7, A-8010 Graz

Tel. $+43316 / 374050$

E-Mail: office@ogka.at, Internet:www.ogka.at 